Review Article

\title{
Vitamin D and Pain: Vitamin D and Its Role in the Aetiology and Maintenance of Chronic Pain States and Associated Comorbidities
}

\author{
Edward A. Shipton and Elspeth E. Shipton \\ Department of Anaesthesia, University of Otago, Christchurch, Corner of Riccarton and Hagley Avenues, \\ Christchurch 8042, New Zealand \\ Correspondence should be addressed to Edward A. Shipton; shiptonea@xtra.co.nz
}

Received 17 January 2015; Accepted 15 March 2015

Academic Editor: Giustino Varrassi

Copyright (C) 2015 E. A. Shipton and E. E. Shipton. This is an open access article distributed under the Creative Commons Attribution License, which permits unrestricted use, distribution, and reproduction in any medium, provided the original work is properly cited.

\begin{abstract}
The emergence of new data suggests that the benefits of Vitamin D extend beyond healthy bones. This paper looks at Vitamin D and its role in the aetiology and maintenance of chronic pain states and associated comorbidities. The interfaces between pain and Vitamin D and the mechanisms of action of Vitamin D on pain processes are explored. Finally the association between Vitamin D and pain comorbidities such as sleep and depression is investigated. The paper shows that Vitamin D exerts anatomic, hormonal, neurological, and immunological influences on pain manifestation, thereby playing a role in the aetiology and maintenance of chronic pain states and associated comorbidities. More research is necessary to determine whether Vitamin D is useful in the treatment of various pain conditions and whether or not the effect is limited to patients who are deficient in Vitamin D.
\end{abstract}

\section{Introduction}

A recent surge of published data on the proven or potential effects of Vitamin D has raised much interest in the medical community. The primary role of Vitamin D is the regulation of serum calcium levels within a narrow range. Vitamin D plays an essential role in bone formation, maintenance, and remodelling, as well as in muscle function. However, the emergence of new data suggests that the benefits of Vitamin $D$ extend beyond healthy bones. Of great interest is the role it could play in optimising neuromuscular functioning, reducing inflammation, and decreasing the risk of many chronic illnesses; these include a variety of cancers, autoimmune diseases, infectious diseases, and cardiovascular diseases [15]. Research has shown that Vitamin D exerts anatomic, hormonal, neurological, and immunological influences on pain manifestation, thereby playing a role in the aetiology and maintenance of chronic pain states and associated comorbidity $[1,6-8]$.

\section{Vitamin D}

2.1. Synthesis, Absorption, and Metabolism of Vitamin D. Chemically, Vitamin D is a fat soluble secosteroid (i.e., a steroid in which one of the bonds in the steroid rings is broken). There are various forms of Vitamin D; the most common forms are Vitamin $\mathrm{D}_{3}$ (cholecalciferol) and Vitamin $\mathrm{D}_{2}$ (ergocalciferol). Both are collectively known as calciferol. Although it is called a vitamin, Vitamin D is really a hormone as it can be produced endogenously by humans. In the skin, 7-dehydrocholesterol is converted to pre-Vitamin $\mathrm{D}_{3}$ by a narrow band of solar ultraviolet radiation $(290-320 \mathrm{~nm})$ that undergoes isomerisation in a temperature-dependent manner to Vitamin $\mathrm{D}_{3}$. Ten thousand to $20,000 \mathrm{IU}$ of Vitamin $\mathrm{D}$ can be produced in 30 minutes of whole-body exposure to sunlight. This endogenously produced Vitamin D enters the blood and binds with Vitamin D binding protein (DBP), facilitating transportation to the liver $[1,5]$. Vitamin D can also be obtained from a limited number of dietary sources. 
Vitamin $\mathrm{D}_{2}$ (ergocalciferol) is produced by some kinds of plants and animals when ergosterol is altered by ultraviolet irradiation. However, few foods have naturally occurring substantial Vitamin $\mathrm{D}_{2}$ levels to make this a significant source of Vitamin D in humans.

Vitamin D from the skin and diet is hydroxylated in the liver by one of several cytochrome P450 enzymes to the prehormone 25-hydroxy Vitamin D [calcidiol, or 25(OH)D] that is encoded by the gene CYP27A1 $[2,5,9]$. Most circulating $25(\mathrm{OH}) \mathrm{D}$ and the active form of Vitamin $\mathrm{D}$, namely, 1,25dihydroxyvitamin $\mathrm{D}\left[1,25(\mathrm{OH})_{2} \mathrm{D}\right]$, are transported in the blood bound to Vitamin D binding protein (DBP) (80-90\%) and to albumin (10-20\%); only a small fraction remains free or unbound [10]. The $25(\mathrm{OH}) \mathrm{D}$ can be taken up by one of two mechanisms, namely, diffusion of free $25(\mathrm{OH}) \mathrm{D}$ across cell membranes throughout the body or a DBP receptor mediated endocytosis by the coreceptors megalin and cubulin [5]. It appears that endocytic transportation may be influenced by certain pathological and physiological determinants [11-13]. The amount of DBP and its effect on free versus bound $25(\mathrm{OH}) \mathrm{D}$ could inversely influence the available free $25(\mathrm{OH}) \mathrm{D}$ for uptake [5]. The primary determinant of how long a Vitamin D metabolite will stay in circulation is its affinity for DBP [14]. Further research is needed to understand the regulation of mobilization of $25(\mathrm{OH}) \mathrm{D}$ from lipid storage pools relative to health outcomes.

However, Vitamin D can also be hydroxylated to $25(\mathrm{OH}) \mathrm{D}$ in all tissues of the body, achieving autocrine production of $25(\mathrm{OH}) \mathrm{D}$ in these tissues [14]. 25(OH)D is then further metabolised in the kidneys and possibly in a wide variety of extrarenal tissues by the enzyme 25-hydroxyvitamin D-1 $\alpha$-hydroxylase (CYP27B1) to its active form, namely, 1,25 -dihydroxyvitamin $\mathrm{D}\left[1,25(\mathrm{OH})_{2} \mathrm{D}_{3}\right]$. Vitamin $\mathrm{D}$ exerts its effects by modulating gene expression after binding to VDR. There appear to be potential genetic polymorphisms in key genes with Vitamin D exposure that can influence bioavailability, transport, and distribution in lipid storage pools, metabolism, and action of Vitamin D [5].

\section{Pain}

Pain is part of the human condition. Pain is defined by the International Association for the Study of Pain (IASP) as "an unpleasant sensory and emotional experience associated with actual or potential tissue damage, or described by the patient in terms of such damage" [15]. Pain is essentially a subjective perceptual experience. Pain originates in the nociceptors of the nervous system but the experience of pain is perceived in the conscious brain. It is influenced by a complex interaction of behavioural, environmental, biological, and societal factors.

There are two broad categories of pain, namely, acute nociceptive pain which acts as an early warning sign and pathological persistent pain, which is essentially an ongoing false alarm $[16,17]$.

Acute pain is a sensation that is elicited after strong stimulation of tissues in the body. Nociception relates to the biochemical and neural changes that occur in response to a noxious stimulus [18]. This stimulation causes action potentials in primary sensory neurones known as nociceptors. These nociceptors are activated by high-threshold stimuli (mechanical, thermal, chemical, or electrical) to transmit excitatory signals to the sensory cell bodies in the dorsal root ganglion (DRG) along the dorsal roots and subsequently into the spinal cord $[16,19]$. In the spinal cord, these primary sensory nerve fibres release neurotransmitters such as amino acids (glutamate) and neuropeptides (such as substance $P$ and calcitonin gene related peptide) that activate second-order neurones. The second-order neurones relay information via specific tracts that reach the thalamus where the sensation of pain occurs. Third-order neurones connecting the thalamus to the somatosensory cortex are activated, resulting in the perception of pain $[16,20]$.

Nociceptors are present in most tissues in the body, including skin, muscle, joints, and viscera. There are predominantly two types of nociceptors involved in the pain pathway, namely, $\mathrm{C}$ fibres and A-delta fibres. The thin, myelinated Adelta fibres are fast transmitting; they are activated by both mechanical and thermal stimuli [18]. The unmyelinated C fibres respond to chemical, thermal, and mechanical stimuli. $\mathrm{C}$ fibres in the viscera are notable in that they respond to noxious stimuli such as the stretching of hollow organs.

The International Association for the Study of Pain (IASP) defines chronic pain as "pain that has persisted beyond normal tissue healing time." This is taken (in absence of other criteria) to be 3 months [21]. However, some chronic pain disorders are characterised by recurrent short acute episodes and exacerbations such as trigeminal neuralgia and rheumatoid arthritis.

Chronic pain can be produced after tissue damage (or inflammation), after nerve damage, and after alteration of normal neural function. Chronic persistent pain leads to chemical, functional, and anatomical changes throughout the nervous system (in the periphery, spinal cord, and brain) [22-24]. The concept of neuroplasticity (the ability of the brain to change its structure and function) can be a positive adaptation to loss of function; in the case of pain, it appears maladaptive [25]. Persistent pain alters the nervous system to produce spontaneous pain that arises without any apparent peripheral stimulus as well as a hypersensitivity to peripheral stimuli $[16,17,26]$. Pain hypersensitivity can result in hyperalgesia (the exaggerated and prolonged response to noxious stimulation) and allodynia (pain resulting from a stimulus that is normally nonpainful) [27]. The reduced descending inhibition in the central nervous system (CNS) results in more peripheral noxious signals getting through to the brain resulting in an increased experience of pain [28].

The transition from acute to chronic pain is not well understood and appears to be multifactorial [29]. Nociceptive pain usually (but not always) reduces with healing. While persistent pain is often due to obvious nerve damage (e.g., injury or cancer), there are many instances when no physical pathology can be objectively verified, such as in fibromyalgia syndrome and in headaches. In general, chronic pain may involve a combination of nociceptive and neuropathic mechanisms, as well as some form of central sensitization and learnt response. The concept of central sensitization is becoming more widely recognised, whereby changes occurring within 
the nervous system result in previously nonnoxious stimuli being perceived as painful, a lowering of the threshold for pain generation, and an increase in the duration, amplitude, and spatial distribution of pain [23]. In addition, central sensitization initiates the interrelationship between many pain problems such as fibromyalgia, irritable bowel, low back pain, and chronic daily headache [30]. Inflammatory and nerve injury are involved in the aetiology of many chronic pain syndromes like osteoarthritis, diabetic neuropathy, or postherpetic neuralgia, but only a small proportion of those subjected to such injuries actually develop chronic pain, and the degree of pain severity can vary significantly between patients [31].

Evidence from large scale studies in Europe, North America, and Australasia has shown that about one in five of the adult population experiences chronic moderate to severe pain with other estimates indicating the prevalence of chronic pain to be closer to 20-25\% [32-34]. The incidence of chronic pain can be higher in at-risk groups such as the elderly and the immune-compromised $[35,36]$. The rate of persistent severe pain among all residents of United States nursing homes in 1999 was found to be $14.7 \%$, with $41.2 \%$ of residents in pain at first assessment experiencing severe pain 60 to 180 days later [37].

The prevalence of chronic pain is projected to increase as the population ages (from around 3.2 million Australians in 2007 to 5.0 million by 2050) [38]. Life-style changes leading to obesity and inactivity will also contribute to increased level of pain in developed countries.

\section{Interfaces of Pain and Vitamin D}

Clinical research in the area of chronic pain and Vitamin D deficiency remains limited. There is a dearth of large double blind randomised controlled studies. However, there is enough evidence showing the potential of Vitamin D to exert anatomic and physiological influences on pain manifestation, thereby playing a role in the aetiology and maintenance of chronic pain states and associated comorbidity $[1,6]$. Persistent pain is associated with Vitamin D-related bone demineralization, myopathy, and musculoskeletal pain. Pain pathways associated with cortical, immunological, hormonal, and neuronal changes are potentially also influenced by Vitamin D levels.

Vitamin D levels have been found to be low in certain groups of patients with various pain states (Box 1) [3943]. Studies of Vitamin D supplementation in patients with known Vitamin D deficiency have shown mixed results in chronic pain patients regarding improved pain scores (Box 1) $[6,9,44-51]$. The prevalence of a variety of pain states at particular latitudes has been linked to low levels of Vitamin $\mathrm{D}$ [52-54]. Seasonal variations correspond with varying pain levels as well [6]. Vitamin D deficiency has been associated with headache, abdominal, knee, and back pain, persistent musculoskeletal pain, costochondritic chest pain, and failed back syndrome and with fibromyalgia [6, 45, 53-59].

Long-term Vitamin D deficiencies have been linked to a weakened immune system and to chronic inflammation [2$4,60]$. Chronic inflammation, in turn, leads to debilitating health conditions; many of these are characterised by pain as the disabling symptom [60]. Serum Vitamin D deficiency $[25(\mathrm{OH}) \mathrm{D}]$ is considered a risk factor for type 1 diabetes, multiple sclerosis, and especially autoimmune rheumatic diseases (ARD) (Box 1). The severity of systemic lupus erythematosus and rheumatoid arthritis has been associated with serum Vitamin D deficiency [61, 62].

Vitamin D deficiency has been linked to other diseases that present with pain as a symptom. Cystic fibrosis patients experience chronic pain in a variety of sites (head, sinuses, back, and chest) [63]. Individuals with cystic fibrosis are at risk of Vitamin D deficiency due to limited sun exposure and malabsorption. Low bone density and osteopaenia appear to contribute to chronic pain in cystic fibrosis patients and are potentially related to low $25(\mathrm{OH})_{2} \mathrm{D}_{3}$ levels $[63,64]$.

Gender differences may be related to Vitamin D deficiency associated with chronic pain. In one large study, prevalence of chronic widespread pain varied by $25(\mathrm{OH}) \mathrm{D}$ concentration in women but not in men [40]. Racial differences in experimental pain are mediated by differences in the Vitamin D levels [65]. Vitamin D deficiency may be a risk factor for increased knee osteoarthritis pain in black Americans.

Individuals suffering from chronic pain usually experience other comorbidities such as sleep, anxiety, and mood disorders. These conditions can impact on the patient's quality of life to a significant extent, resulting in loss of employment and/or withdrawal from social life. Adequate levels of Vitamin D have been associated with improved quality of life indicators [48, 66-68]. Significant improvements in assessment of sleep, pain levels, well-being, and various aspects of quality of life with Vitamin D supplementation have been shown $[48,66-69]$.

4.1. Pain Associated with Vitamin D-Related Bone Demineralization. In the absence of bone mineralisation due to Vitamin $\mathrm{D}$ deficiency, weight-bearing growing bones (arms and legs) of infants and children become bowed. In infants, rickets may result in delayed closing of the fontanelles and in rib cage deformities [3]. Subtle evidence of rickets in children includes leg pain, delayed age for standing and walking, and delayed growth.

Adult bones undergo a constant state of remodeling. Decreased levels of $25(\mathrm{OH}) \mathrm{D}$ facilitate osteoclast genesis with consequent increased bone resorption [9]. Inadequate mineralisation of the collagen matrix due to low calcium and phosphate levels results in osteomalacia. Bone pain and proximal muscle weakness with gait instability are characteristic of osteomalacia [3, 9]. Decreased levels of $25(\mathrm{OH}) \mathrm{D}$ have been shown to be directly related to low bone density in the hip $[9,70]$.

4.2. Pain Associated with Vitamin D Deficiency and Muscle Weakness. Vitamin D deficiency causes muscle weakness and pain in children and adults. Individuals with chronic low back pain have been found to have weaker gluteus medius muscles than control subjects without back pain [71]. The incidence of low back pain is associated with isometric and isokinetic trunk extensor weakness, whereas low back pain severity is 
(i) Headache

(ii) Cancer pain

(iii) Persistent musculoskeletal pain and weakness (rickets, osteomalacia, osteopaenia, cystic fibrosis, back pain, knee pain, and costochondritic chest pain)

(iv) Fibromyalgia

(v) Abdominal pain

(vi) Pain associated with ischaemia (sickle cell disease and coronary artery disease)

(vii) Inflammatory pain (rheumatoid arthritis and systemic lupus erythematosus)

(viii) Neuropathic pain (diabetic neuropathy, post herpetic neuropathy, and multiple sclerosis)

Box 1: Interfaces of Vitamin D deficiency and types of persistent pain.

associated with isokinetic trunk extensor and flexor weakness and isometric trunk extensor and flexor weakness [72].

Vitamin $\mathrm{D}$ has an important role in the regulation of serum calcium concentration and in muscle protein synthesis. Vitamin D increases the serum calcium level that is essential for muscle contraction; protein synthesis affects muscle growth [73]. This process is mediated by the nuclear vitamin $\mathrm{D}$ receptor (VDR) and by a variety of nongenomic effects [74]. VDRs are found in muscle tissue. Vitamin D improves musculoskeletal function by exerting a direct effect on the muscle tissue itself $[75,76]$. Vitamin D deficiency primarily affects the faster and stronger type 2 muscle fibres. This may explain why supplementation with Vitamin D improves proximal muscle strength. Hypovitaminosis D impairs neuromuscular coordination, as measured by body sway. It increases the risk of falling and painful fractures related to falls in the elderly [73, 74, 77-80]. It has been postulated that there is a genetic predisposition to the decline in strength in elderly women that is linked to the VDR [81].

Musculoskeletal pain related to osteomalacia may probably be due to spongy matrix formation under the periosteal membranes caused by demineralization of the bone [82]. This gelatin-like collagen matrix can expand when it becomes hydrated; it causes outward pressure on periosteal tissues that are richly innervated with sensory pain fibres. This pressure results in a throbbing, aching bone pain [82].

4.3. Mechanisms of Action of Vitamin D on Pain Processes. There are a number of mechanisms involved in the development of neuropathic pain after peripheral nerve damage (Box 2). These include ectopic excitability of sensory neurones, altered gene expression of sensory neurones, and sensitisation of neurones in the dorsal horn of the spinal cord [27]. These mechanisms are influenced by a number of biological and psychosocial factors. Neurotransmitters such as glutamate, substance $\mathrm{P}$, serotonin, and gammaaminobutyric acid (GABA) as well as glial inflammation are central to the excitatory and inhibitory influences on pain.

Inflammatory pain and neuropathic pain may depend on the action of diverse cytokines and other molecules; these include eicosanoids, endorphins, calcitonin-generelated peptides (CGRP), and transcription factors. Because steroid compounds (including hormonal steroids, neurosteroids, and synthetic analogues of neuroactive steroids) control the plasticity of the nervous system, these compounds are of particular interest in the modulation of pain [83].

4.3.1. Vitamin D as a Neuroactive Steroid. Vitamin D can modulate neuronal excitability similar to that of other neuroactive steroids (Box 2) [84]. This includes spontaneous regular firing, action potential duration, intrinsic excitability, and sensitivity to neurotransmitters as well as to neurotransmitter receptors such as GABA receptor and N-methylD-aspartate (NMDA) receptor [85-87]. Steroid hormones influence the electrical activity of many neurones and effectors by regulating transcription of their ion channels and neurotransmitter receptors, or by modulating the activity of their channels and receptors through second messengercoupled membrane receptors [85]. Vitamin D as a neuroactive steroid activates a variety of signal transduction systems. These include calcium ion influx, the release of calcium ions from intracellular stores, the modulation of adenylate cyclase, phospholipase C (PLC), protein kinase C, protein kinase $\mathrm{D}$, the mitogen-activated protein (MAP) kinases, and the rapidly accelerated fibrosarcoma (Raf) kinase pathways [88]. As a steroid, Vitamin D modulates brain neurotransmitters (acetylcholine, dopamine, and serotonin) as well [84].

4.3.2. Vitamin D and Neurotrophins. Vitamin D upregulates the synthesis of neurotrophins such as neural growth factor (NGF), neurotrophin 3 (NT3), and glial cell linederived neurotrophic factor (GDNF), whereas neurotrophin 4 (NT4) is downregulated (Box 2) [89-92]. Through this system, Vitamin D can potentially affect the development, maintenance, and survival of neurones. NGF is a wellestablished inflammatory mediator. It has direct effects on the sensory nerve endings causing hypersensitivity, amplification of sensory input signals, and enhanced innervation of injured tissue [93-95]. In the diabetic neuropathic pain model, Vitamin D supplementation has been shown to increase NGF production and prevent neurotrophic deficits [91]. There is some evidence that Vitamin D exercises a neuroprotective function by attenuating the effects of glucocorticoids and by modulating neuronal calcium ion homeostasis [96, 97].

VDRs have been localised in neurones and in glial cells [98]. Genes encoding the enzymes involved in the metabolism of Vitamin D are expressed in brain cells [98]. It has been suggested that the local synthesis of $1,25(\mathrm{OH})_{2} \mathrm{D}_{3}$ 
(i) Vitamin D as a neuroactive steroid modulates neuronal excitability and brain neurotransmitters and activates a variety of signal transduction systems

(ii) Vitamin D influences prostaglandin action by inhibiting COX-2 expression and by stimulating 15-prostaglandin dehydrogenase (15-PGDH) expression that degrades prostaglandins that would have lowered the firing threshold of sensory neurones

(iii) Vitamin D inhibits synthesis of nitric oxide synthase (iNOS), the enzyme that produces nitric oxide (NO, a neurotransmitter involved in nociceptive process that contributes to development of central sensitization) in macrophages that activate microglia and astrocytes

(iv) VDR, $1 \alpha$-hydroxylase, and vitamin D binding protein in the hypothalamus are suggested as mechanism by which Vitamin D deficiency is implicated in pathophysiology of various primary headache disorders

(v) Vitamin D upregulates synthesis of neurotrophins affecting development, maintenance, and survival of neurones

(vi) Vitamin D affects a number of inflammatory pathways associated with chronic pain by upregulating transforming growth factor beta 1 (TGF- $\beta 1$ ) in astrocytes and microglia that suppresses activity of various cytokines

(vii) Vitamin D suppresses tumour necrosis factor alpha (TNF- $\alpha$ ) and macrophage colony-stimulating factor (M-CSF) in astrocytes and microglia and inhibits pain pathways

(viii) Vitamin D inhibits T-helper cell over activity and plays an important role in preventing autoimmune diseases

Box 2: Mechanisms of action of Vitamin D on pain processes.

by microglia could stimulate an antitumour response; this is because $1,25(\mathrm{OH})_{2} \mathrm{D}_{3}$ causes cell death and redifferentiation programs in glioma cells [92].

In other circumstances, microglia contribute to neuropathic pain after peripheral nerve injury [93, 99-101]. Vitamin D plays a fundamental role in astrocyte detoxification pathways, thereby exerting a neuroprotective effect [90]. Vitamin D increases the synthesis of several neurotrophins in astrocytes; these include NGF, NT3, and GDNF and $\gamma$ glutamyl transpeptidase (another mechanism involved in neuroprotection) [92].

4.3.3. Vitamin D and Prostaglandins. Vitamin D influences prostaglandin action by inhibiting COX-2 expression and by stimulating 15-prostaglandin dehydrogenase (15PGDH) expression [102]. The enzyme 15-PGDH degrades prostaglandins and inhibits prostaglandin-E2 receptor (PGE2) subtypes and prostaglandin-F2 alpha receptor subtypes (Box 2) [102]. Prostaglandins have a direct effect on sensory neurones by lowering the firing threshold, increasing the number of action potentials elicited by a depolarizing stimulus, and enhancing SP and CGRP release [103]. Prostaglandins mediate neuropathic pain in the spinal cord via PGE2 depolarising wide dynamic range neurones [27].

4.3.4. Vitamin D Effects on Inflammatory Pathways. Vitamin $\mathrm{D}$ is known to affect a number of inflammatory pathways associated with the development and persistence of chronic pain (Box 2). Vitamin D upregulates transforming growth factor beta 1 (TGF- $\beta 1$ ) and interleukin-4 (IL-4) found in astrocytes and microglia [92]. TGF- $\beta 1$ suppresses the activity of various cytokines, namely, interferon- $\gamma$, TNF- $\alpha$, and various T cells such as interleukin-1 (IL-1) and interleukin-2 (IL2 ). It can downregulate the activity of immune cells through suppression of cytokine receptors (such as the IL-2 receptor) [104].

Vitamin D suppresses TNF- $\alpha$ and macrophage colonystimulating factor (M-CSF) in astrocytes and microglia [92]. TNF- $\alpha$ has been convincingly implicated at both peripheral and central levels of sensitization [105]. M-CSF is a cytokine that stimulates proliferation, differentiation, and survival of monocytes and macrophages. Macrophages can release many inflammatory mediators, including proinflammatory cytokines, particularly TNF- $\alpha$ and interleukin-1-beta (IL-1 $\beta$ ), NGF, NO (nitric oxide), and prostanoids [93]. By limiting $\mathrm{M}-$ CSF, Vitamin D has the potential to inhibit pain pathways.

4.3.5. Vitamin D and Nitric Oxide Synthase. Vitamin D has also been found to inhibit the synthesis of nitric oxide synthase (iNOS), the enzyme that produces nitric oxide (NO), in macrophages that activates microglia and astrocytes at both protein and m-RNA levels (Box 2) [106]. NO is an important neurotransmitter involved in the nociceptive process; in the dorsal horn of the spinal cord, it contributes to the development of central sensitization [107]. Astrocytes play a pivotal role in central nervous system (CNS) detoxification pathways, where glutathione (GSH) is involved in the elimination of nitric oxide. The activity of gamma-glutamyl transpeptidase (gamma-GT), an enzyme of central significance in GSH metabolism, has been shown to be regulated by 1,25-dihydroxyvitamin $\mathrm{D}_{3}\left[1,25(\mathrm{OH})_{2} \mathrm{D}_{3}\right]$ causes cell death [108]. The inhibition of iNOS by Vitamin D is a potential mechanism for reducing pain and neuronal damage after injury or in diseases such as ischaemia, Parkinson's disease, and acquired immune-deficiency syndrome (AIDS) [92, 93].

4.3.6. Vitamin D and T-Helper Cells. Several immune cell types contribute to peripheral neuropathy and to the development of neuropathic pain. Mast cells are released by injured nerves; they appear to reduce the recruitment of neutrophils and monocytes into the injured nerve, potentially reducing the release of chemokines and other mediators. Vitamin D downregulates neutrophil function [109]. Neutrophils produce various inflammatory factors (lipoxygenase products, nitric oxide, and cytokines) [93]. High levels of neutrophils are released after tissue injury and are linked to the development of symptoms of neuropathic pain [110]. The hyperalgesic actions of NGF appear to be partly dependent on 
neutrophil accumulation [93]. Vitamin D inhibits T-helper cell overactivity and plays an important role in the prevention of autoimmune diseases (Box 2) [111].

4.3.7. Vitamin D Receptor (VDR) and $1 \alpha$-Hydroxylase. VDR and $1 \alpha$-hydroxylase [the enzyme that converts $25(\mathrm{OH}) \mathrm{D}$ by hydroxylation to the active $1,25(\mathrm{OH})_{2} \mathrm{D}_{3}$ ] are found in many areas of the human central nervous system. These include the prefrontal cortex, amygdala, raphe, substantia gelatinosa, cerebellum, hippocampus, cingulate gyrus, substantia nigra, thalamus, and hypothalamus [84]. Both the receptor and the enzyme have been demonstrated in neuronal and glial cells as well [112]. In the rat model, Vitamin D binding protein has been found in axonal projections in the lateral hypothalamus [113]. The presence of VDRs, $1 \alpha$-hydroxylase, and Vitamin $\mathrm{D}$ binding protein in the hypothalamus is suggested as the mechanism by which Vitamin D deficiency is implicated in the pathophysiology of various primary headache disorders (Box 2) [52].

\section{Vitamin D Associated with Pain Comorbidities (Sleep and Depression)}

Anatomical and the functional colocalization of central serotonergic, noradrenergic, and dopaminergic systems involved in pain, sleep, Vitamin D, and depression also tend to point to some interconnectivity (Box 3 ). The enzyme 1 alphahydroxylase which converts 25-OHD to the active Vitamin $\mathrm{D}$ is present in the hypothalamus, cerebellum, and substantia nigra, areas that are also associated with depression. VDRs are widespread in the human central nervous system, including neurones and glia in many areas of the cingulated cortex and hippocampus, which have been implicated in the pathophysiology of depression [114]. Vitamin D receptors are also present in the anterior and posterior hypothalamus, substantia nigra, midbrain periaqueductal gray (PAG), raphe nuclei, and the nuclei reticularis pontis oralis and caudalis. These same areas play a role in the initiation and maintenance of sleep. Vitamin D's effects on these brain areas may be linked to sleep modulation [115].

There appears to be considerable overlap in the effects of sleep, pain, depression, and Vitamin D on the immune system. Vitamin D could be linked to depression, sleep, and chronic pain by mediating effects of immune cells such as astrocytes and macrophages (Box 3) [90, 92]. Vitamin D directly affects $\mathrm{T}$ cell responses inhibiting the production of IL-2, interleukin-17 (IL-17), and interleukin-21 (IL-21) and by stimulating interleukin-4 (IL-4) production [116].

Chronic sleep loss impairs immune function. This results in increases in proinflammatory mediators such as cytokines and chemokines $[117,118]$. Cytokines (especially IL-1beta and $\mathrm{TNF}-\alpha$ ) are implicated in the regulation of sleep and modulation of sleep architecture and appear to be involved in circadian regulation of sleep [118-121].

There are suggestions of a bidirectional feedback loop between sleep and cytokine expression [118]. Insufficient sleep quantity may facilitate or exacerbate pain through elevations of interleukin-6 (IL-6) [122]. In disorders where sleep disturbances are common, insufficient sleep quantity itself may establish and maintain its cooccurrence with pain and with increased inflammation [122]. Vitamin D deficiency could contribute to poor quality sleep or symptoms of impaired wakefulness by inducing a relative elevation of circulating TNF- $\alpha$ and nuclear factor kappa-light-chainenhancer of activated $\mathrm{B}$ cells $(\mathrm{NF} \kappa \mathrm{B})$, both of which can result in subjective feeling of sleepiness [123].

Patients with depressive symptoms and with pain disorders display enhanced cytokine levels. These include IL6 , C-reactive protein (CRP), IL-1B, and TNF- $\alpha$ [124]. Major depression may be accompanied by systemic immune activation or an inflammatory response with involvement of phagocytic (monocytes, neutrophils) cells, T cell activation, increased prostaglandin secretion, and increased production of IL- $1 \beta$ and IL- 6 by peripheral blood mononuclear cells [125]. Cytokines also play a central role in the generation and transmission of pain with increased levels of TNF- $\alpha$ and IL-1, IL-2, and IL-6, and decreased levels of IL-4 and IL-10 $[126,127]$. Cytokines have been shown to modulate the central metabolism of serotonin and dopamine [128].

IL-1 stimulates the synthesis and/or release of growth hormone releasing hormone, prostaglandin- $\mathrm{D}_{2}$, adenosine, and nitric oxide. These are substances that are implicated in regulation of non-REM sleep [117]. Vitamin D has been shown to downregulate these substances [106]. Vitamin D, chronic pain, sleep, and depression are intimately linked to the nervous, endocrine, metabolic, and immune systems of the body and their mediators. These mediators include neurotransmitters, neuropeptides, hormones, and cytokines $[117,119,129]$.

There are four key neurotransmitters involved in Vitamin $\mathrm{D}$, pain, and depression, namely, serotonin, noradrenaline, substance $\mathrm{P}$, and dopamine. Serotonin levels are typically low in depressed patients $[130,131]$. Serotonin can have pronociceptive or antinociceptive effects, depending on the receptor subtype and location in the central nervous system. Serotonin can be pronociceptive in the periphery, whereas the primary antinociceptive effects of serotonin are thought to occur via receptors located centrally in the descending antinociceptive pathways [132].

Chronic sleep loss has also been shown to have an effect on a variety of neurotransmitters involved in sleep regulation via increase in IL-1 [117]. IL-1 inhibits acetylcholine release and can potentiate or inhibit the effects of glutamate and has been linked to the stimulation of adenosine and monoamine release, thereby playing a role in sleep homeostasis [117, 119]. IL-1 and TNF also interact with the serotonin system to enhance non-REM sleep [133]. IL-1 reduces the firing rate of wake-active serotonergic neurones by potentiating the inhibitory effects of gamma-aminobutyric acid (GABA) [134]. IL-1 in the preoptic area (POA) of the hypothalamus and the adjoining magnocellular basal forebrain (BF) appears to be controlled by corticosteroids released into the blood by the adrenal cortex. Corticosteroid levels depend on the activity of the hypothalamic-pituitary-adrenal axis that is stimulated by the activation of the serotonin pathway [117]. As mentioned previously, IL-1 and TNF have a direct action sensitising nociceptors, enhancing excitatory currents, and reducing inhibitory pain pathways [135]. 
(i) Anatomical colocalization and functional interaction of central serotonergic, noradrenergic, and dopaminergic systems.

(ii) Inhibition or potentiation of other neurotransmitters such as substance P, acetylcholine, glutamate, adenosine, GABA, and monoamine.

(iii) Mediation of immune cells such as astrocytes, macrophages, and phagocytic (monocytes, neutrophils) cells.

(iv) Immune system modulation of proinflammatory mediators such as cytokines and chemokines, especially IL-1beta and TNF- $\alpha$, and including NF $\kappa$ B, IL-2, IL-6, and CRP.

(v) Immune system modulation of T cell responses inhibiting the production of IL-2, IL-17, and IL-21, and by stimulating IL-4 and IL-10 production.

(vi) Immune system modulation via synthesis and/or release of growth hormone releasing hormone, prostaglandin- $\mathrm{D}_{2}$, adenosine, and $\mathrm{NO}$.

(vii) Influence on the hypothalamus-pituitary-adrenal axis and corticosteroid levels

Box 3: Potential interfaces of Vitamin D, pain, sleep, and depression.

Dopamine is integral to the regulation of sleep and wake $[136,137]$. Dopamine has been shown to moderate motivation and reward-related behaviour that are typically disrupted in depression [138]. Dopamine also appears to have an antinociceptive effect at both spinal and supraspinal levels. It has an important role in descending inhibition of pain pathways [139].

The reduced synthesis of dopamine in the nucleus accumbens during prolonged exposure to unavoidable stress results in the development of persistent hyperalgesia [140]. Low dopamine levels have been associated with painful symptoms related to fibromyalgia as well [139].

It has also been suggested that serotonergic raphe cells involved in alertness become dysregulated during chronic pain and contribute to sleep disruption and sleep loss [136, 141]. Sleep deprivation has been shown in preclinical studies to dysregulate endogenous opioid systems and reduce the analgesic efficacy of mu-opioid receptor agonists, thereby modulating pain systems $[142,143]$. Acetylcholine, adenosine, and GABA are all known to modulate sleep and pain [144]. The pontine reticular formation plays a key role in rapid eye movement (REM) sleep generation and may regulate centralpain processing mechanisms $[144,145]$.

Depressed patients showed reduced cerebrospinal fluid levels of noradrenaline [146]. Noradrenaline primarily has an antinociceptive effect on the alpha- 2 adrenoreceptors in the descending pain pathways centrally by reducing the sensitivity of the dorsal horn neurones to noxious stimuli [147]. However, like serotonin, noradrenaline can also have a lesser pronociceptive effect on the periphery in sympathetically mediated pain [148].

Substance $\mathrm{P}$ has been shown to be an important neurotransmitter in pain and depression [149]. Raised cerebral spinal fluid (CSF) levels of substance $\mathrm{P}$ have been found in patients with depression [124]. Substance P contributes to central sensitization in persistent pain $[149,150]$. Since substance $\mathrm{P}$ has been found to be to be present in central serotonergic, noradrenergic, and dopaminergic systems, researchers believe that it may be an important modulator in depression and pain [124].
Proinflammatory cytokines potently activate the hypothalamus-pituitary-adrenal axis [151]. This effect is usually attributed to increased production of corticotrophinreleasing factor (CRF) [151]. CRF appears to have an important role in both depression and pain. Raised levels of CRF have been linked to melancholic depression [152]. CRF has also been shown to be antinociceptive in the central nervous system as well as in the periphery [153]. A hyperactive hypothalamus-pituitary-adrenal (HPA) axis is often associated with clinical depression [151]. Vitamin D modulates this axis by regulating adrenaline, noradrenaline, and dopamine production through VDRs in the adrenal cortex and protects against the depletion of dopamine and serotonin centrally.

\section{Conclusion}

In summary, low Vitamin D levels are implicated in various chronic pain conditions. Research has shown that Vitamin D exerts anatomic, hormonal, neurological, and immunological influences on pain manifestation, thereby playing a role in the aetiology and maintenance of chronic pain states and associated comorbidity $[1,6-8]$. More research is necessary to determine whether Vitamin D is useful in the treatment of various pain conditions and whether or not the effect is limited to patients who are deficient in Vitamin D [43].

\section{Conflict of Interests}

The authors declare no conflict of interests regarding the publication of this paper.

\section{References}

[1] M. F. Holick, "Vitamin D deficiency," The New England Journal of Medicine, vol. 357, no. 3, pp. 266-281, 2007.

[2] K. K. Deeb, D. L. Trump, and C. S. Johnson, "Vitamin D signalling pathways in cancer: potential for anticancer therapeutics," Nature Reviews Cancer, vol. 7, no. 9, pp. 684-700, 2007.

[3] T. D. Thacher and B. L. Clarke, "Vitamin D insufficiency," Mayo Clinic Proceedings, vol. 86, no. 1, pp. 50-60, 2011. 
[4] K. L. Munger, L. I. Levin, B. W. Hollis, N. S. Howard, and A. Ascherio, "Serum 25-hydroxyvitamin D levels and risk of multiple sclerosis," Journal of the American Medical Association, vol. 296, no. 23, pp. 2832-2838, 2006.

[5] P. M. Brannon, "Key questions in Vitamin D research," Scandinavian Journal of Clinical and Laboratory Investigation Supplementum, vol. 243, pp. 154-162, 2012.

[6] G. A. Plotnikoff and J. M. Quigley, "Prevalence of severe hypovitaminosis $\mathrm{D}$ in patients with persistent, nonspecific musculoskeletal pain," Mayo Clinic Proceedings, vol. 78, no. 12, pp. 1463-1470, 2003.

[7] M. Cutolo, S. Paolino, A. Sulli, V. Smith, C. Pizzorni, and B. Seriolo, "Vitamin D, steroid hormones, and autoimmunity," Annals of the New York Academy of Sciences, vol. 1317, no. 1, pp. 39-46, 2014.

[8] C. A. S. Jesus, D. Feder, and M. F. P. Peres, "The role of vitamin $\mathrm{D}$ in pathophysiology and treatment of fibromyalgia," Current Pain and Headache Reports, vol. 17, no. 8, p. 355, 2013.

[9] J. S. Adams and M. Hewison, "Update in vitamin D," The Journal of Clinical Endocrinology and Metabolism, vol. 95, no. 2, pp. 471$478,2010$.

[10] J. Zerwekh, "Blood biomarkers of vitamin D status 1, 2, 3, 4," The American Journal of Clinical Nutrition, vol. 87, no. 4, pp. 1087S1091S, 2008.

[11] O. A. Gressner, B. Lahme, and A. M. Gressner, "Gc-globulin (vitamin D binding protein) is synthesized and secreted by hepatocytes and internalized by hepatic stellate cells through $\mathrm{Ca}^{2+}$-dependent interaction with the megalin/gp330 receptor," Clinica Chimica Acta, vol. 390, no. 1-2, pp. 28-37, 2008.

[12] G. J. Atkins, P. H. Anderson, D. M. Findlay et al., "Metabolism of vitamin D3 in human osteoblasts: evidence for autocrine and paracrine activities of 1 alpha, 25-dihydroxyvitamin D3," Bone, vol. 40, no. 6, pp. 1517-1528, 2007.

[13] T. E. Willnow and A. Nykjaer, "Cellular uptake of steroid carrier proteins-mechanisms and implications," Molecular and Cellular Endocrinology, vol. 316, no. 1, pp. 93-102, 2010.

[14] B. W. Hollis and C. L. Wagner, "The role of the parent compound vitamin $\mathrm{D}$ with respect to metabolism and function: why clinical dose intervals can affect clinical outcomes," Journal of Clinical Endocrinology and Metabolism, vol. 98, no. 12, pp. 46194628, 2013.

[15] H. Merskey and N. Bogduk, Classification of Chronic Pain: Descriptions of Chronic Pain Syndromes and Definitions of Pain Terms, IASP Press, Seattle, Wash, USA, 2nd edition, 1994.

[16] A. Basbaum, C. Bushnell, and M. Devor, "Pain: basic mechanisms," in Pain 2005: An Updated Review: Refresher Course Syllabus, D. Justins, Ed., pp. 3-12, IASP Press, Seattle, Wash, USA, 2005.

[17] C. J. Woolf and Q. Ma, "Nociceptors-noxious stimulus detectors," Neuron, vol. 55, no. 3, pp. 353-364, 2007.

[18] P. Suchdev, "Pathophysiology of pain," in Manual of Pain Management, C. Warfield and H. Fausett, Eds., pp. 6-10, Lippincott Williams \& Wilkins, Philadelphia, Pa, USA, 2nd edition, 2002.

[19] F. Porrec, "Nociceptors, the spinal dorsal horn, and descending modulation," in Pain 2012: Refresher Courses, 14th World Congress on Pain, I. Tracey, Ed., pp. 3-14, IASP Press, Seattle, DC, USA, 2012.

[20] T. W. Vanderah, "Pathophysiology of pain," The Medical Clinics of North America, vol. 91, no. 1, pp. 1-12, 2007.

[21] International Association for the Study of Pain, "Classification of chronic pain,” Pain, supplement 3, pp. S1-S226, 1986.
[22] F. Seifert and C. Maihöfner, "Functional and structural imaging of pain-induced neuroplasticity," Current Opinion in Anaesthesiology, vol. 24, no. 5, pp. 515-523, 2011.

[23] A. Latremoliere and C. J. Woolf, "Central sensitization: a generator of pain hypersensitivity by central neural plasticity," Journal of Pain, vol. 10, no. 9, pp. 895-926, 2009.

[24] H. Flor, T. Elbert, S. Knecht et al., "Phantom-limb pain as a perceptual correlate of cortical reorganization following arm amputation," Nature, vol. 375, no. 6531, pp. 482-484, 1995.

[25] P. J. Siddall, "Neuroplasticity and pain: what does it all mean?" Medical Journal of Australia, vol. 198, no. 4, pp. 177-178, 2013.

[26] C. Stein, “Opioids, sensory systems and chronic pain," European Journal of Pharmacology, vol. 716, no. 1-3, pp. 179-187, 2013.

[27] G. Moalem and D. J. Tracey, "Immune and inflammatory mechanisms in neuropathic pain," Brain Research Reviews, vol. 51, no. 2, pp. 240-264, 2006.

[28] P. J. Siddall and M. J. Cousins, "Persistent pain as a disease entity: implications for clinical management," Anesthesia and Analgesia, vol. 99, no. 2, pp. 510-520, 2004.

[29] E. A. Shipton, "The transition from acute to chronic post surgical pain," Anaesthesia and Intensive Care, vol. 39, no. 5, pp. 824-836, 2011.

[30] C. J. Woolf, "Central sensitization: Implications for the diagnosis and treatment of pain," Pain, vol. 152, no. 3, pp. S2-S15, 2011.

[31] I. Belfer, "Nature and nurture of human pain," Scientifica, vol. 2013, Article ID 415279, 19 pages, 2013.

[32] F. M. Blyth, L. M. March, A. J. M. Brnabic, L. R. Jorm, M. Williamson, and M. J. Cousins, "Chronic pain in Australia: a prevalence study," Pain, vol. 89, no. 2-3, pp. 127-134, 2001.

[33] H. Breivik, B. Collett, V. Ventafridda, R. Cohen, and D. Gallacher, "Survey of chronic pain in Europe: prevalence, impact on daily life, and treatment," European Journal of Pain, vol. 10, no. 4, pp. 287-333, 2006.

[34] D. Hoy, C. Bain, G. Williams et al., "A systematic review of the global prevalence of low back pain," Arthritis and Rheumatism, vol. 64, no. 6, pp. 2028-2037, 2012.

[35] A. Abdulla, N. Adams, M. Bone et al., "Guidance on the management of pain in older people," Age and Ageing, vol. 42, supplement 1, pp. 1-57, 2013.

[36] P. M. Grace, M. R. Hutchinson, S. F. Maier, and L. R. Watkins, "Pathological pain and the neuroimmune interface," Nature Reviews Immunology, vol. 14, no. 4, pp. 217-231, 2014.

[37] J. M. Teno, S. Weitzen, T. Wetle, and V. Mor, "Persistent pain in nursing home residents," The Journal of the American Medical Association, vol. 285, no. 16, p. 2081, 2081.

[38] Economics A. The High Price of Pain: The Economic Impact of Persistent Pain in Australia, MBF Foundation, 2007.

[39] P. L. Kaza and T. Moulton, "Severe vitamin D deficiency in a patient with sickle cell disease: a case study with literature review," Journal of Pediatric Hematology/Oncology, vol. 36, no. 4, pp. 293-296, 2014.

[40] K. Atherton, D. J. Berry, T. Parsons, G. J. Macfarlane, C. Power, and E. Hyppönen, "Vitamin D and chronic widespread pain in a white middle-aged British population: evidence from a crosssectional population survey," Annals of the Rheumatic Diseases, vol. 68, no. 6, pp. 817-822, 2009.

[41] S. Straube, S. Derry, R. A. Moore, and H. J. McQuay, "Vitamin D for the treatment of chronic painful conditions in adults," The Cochrane Database of Systematic Reviews, no. 1, Article ID CD007771, 2010. 
[42] J. Bartley, "Prevalence of vitamin D deficiency among patients attending a multidisciplinary tertiary pain clinic," New Zealand Medical Journal, vol. 121, no. 1286, pp. 57-62, 2008.

[43] M. Z. Erkal, J. Wilde, Y. Bilgin et al., "High prevalence of vitamin D deficiency, secondary hyperparathyroidism and generalized bone pain in Turkish immigrants in Germany: identification of risk factors," Osteoporosis International, vol. 17, no. 8, pp. 11331140, 2006.

[44] P. J. van Veldhuizen, S. A. Taylor, S. Williamson, and B. M. Drees, "Treatment of vitamin D deficiency in patients with metastatic prostate cancer may improve bone pain and muscle strength," Journal of Urology, vol. 163, no. 1, pp. 187-190, 2000.

[45] A. Lotfi, A. M. Abdel-Nasser, A. Hamdy, A. A. Omran, and M. A. El-Rehany, "Hypovitaminosis D in female patients with chronic low back pain," Clinical Rheumatology, vol. 26, no. 11, pp. 1895-1901, 2007.

[46] S. Al Faraj and K. Al Mutairi, "Vitamin d deficiency and chronic low back pain in Saudi Arabia," Spine, vol. 28, no. 2, pp. 177-179, 2003.

[47] G. de Torrenté de la Jara, A. Pécoud, and B. Favrat, "Female asylum seekers with musculoskeletal pain: the importance of diagnosis and treatment of hypovitaminosis D," BioMedical Central Family Practice, vol. 7, article 4, 2006.

[48] W. Huang, S. Shah, Q. Long, A. K. Crankshaw, and V. Tangpricha, "Improvement of pain, sleep, and quality of life in chronic pain patients with vitamin D supplementation," Clinical Journal of Pain, vol. 29, no. 4, pp. 341-347, 2013.

[49] J. Iwamoto, T. Takeda, S. Ichimura, K. Matsu, and M. Uzawa, "Effects of cyclical etidronate with alfacalcidol on lumbar bone mineral density, bone resorption, and back pain in postmenopausal women with osteoporosis," Journal of Orthopaedic Science, vol. 8, no. 4, pp. 532-537, 2003.

[50] G. de Torrenté de la Jara, A. Pécoud, and B. Favrat, "Musculoskeletal pain in female asylum seekers and hypovitaminosis $\mathrm{D}_{3}$," British Medical Journal, vol. 329, no. 7458, pp. 156-157, 2004.

[51] P. Lee and R. Chen, "Vitamin D as an analgesic for patients with type 2 diabetes and neuropathic pain," Archives of Internal Medicine, vol. 168, no. 7, pp. 771-772, 2008.

[52] S. Prakash, N. C. Mehta, A. S. Dabhi, O. Lakhani, M. Khilari, and N.D. Shah, "The prevalence of headache may be related with the latitude: a possible role of Vitamin D insufficiency?” The Journal of Headache and Pain, vol. 11, no. 4, pp. 301-307, 2010.

[53] M. Saps, C. Blank, S. Khan et al., "Seasonal variation in the presentation of abdominal pain," Journal of Pediatric Gastroenterology and Nutrition, vol. 46, no. 3, pp. 279-284, 2008.

[54] D. D. Mitsikostas, D. Tsaklakidou, N. Athanasiadis, and A. Thomas, "The prevalence of headache in Greece: correlations to latitude and climatological factors," Headache, vol. 36, no. 3 , pp. 168-173, 1996.

[55] Q. Y. Zeng, R. Chen, Z. Y. Xiao et al., "Low prevalence of knee and back pain in southeast China; the Shantou COPCORD study," The Journal of Rheumatology, vol. 31, no. 12, pp. 24392443, 2004.

[56] H. Glerup, K. Mikkelsen, L. Poulsen et al., "Commonly recommended daily intake of vitamin $\mathrm{D}$ is not sufficient if sunlight exposure is limited," Journal of Internal Medicine, vol. 247, no. 2, pp. 260-268, 2000.

[57] D. S. Arvold, M. J. Odean, M. P. Dornfeld et al., "Corelation of symptoms with vitamin $\mathrm{D}$ deficiency and symptom response to cholecalciferol treatment: a randomized controlled trial," Endocrine Practice, vol. 15, no. 3, pp. 203-212, 2009.
[58] R. C. Oh and J. D. Johnson, "Chest pain and costochondritis associated with vitamin D deficiency: a report of two cases," Case Reports in Medicine, vol. 2012, Article ID 375730, 3 pages, 2012.

[59] S. Waikakul, "Serum 25-hydroxy-calciferol level and failed back surgery syndrome," Journal of Orthopaedic Surgery (Hong Kong), vol. 20, no. 1, pp. 18-22, 2012.

[60] B. N. Ames, "Low micronutrient intake may accelerate the degenerative diseases of aging through allocation of scarce micronutrient by triage," Proceedings of the National Academy of Sciences of the United States of America, vol. 103, no. 47, pp. 17589-17594, 2006.

[61] L. L. Ritterhouse, S. R. Crowe, T. B. Niewold et al., "Vitamin D deficiency is associated with an increased autoimmune response in healthy individuals and in patients with systemic lupus erythematosus," Annals of the Rheumatic Diseases, vol. 70, no. 9, pp. 1569-1574, 2011.

[62] K. Gopinath and D. Danda, "Supplementation of 1,25 dihydroxy vitamin $\mathrm{D}_{3}$ in patients with treatment naive early rheumatoid arthritis: a randomised controlled trial," International Journal of Rheumatic Diseases, vol. 14, no. 4, pp. 332-339, 2011.

[63] M. Hayes, M. Yaster, J. A. Haythornthwaite et al., "Pain is a common problem affecting clinical outcomes in adults with cystic fibrosis," Chest, vol. 140, no. 6, pp. 1598-1603, 2011.

[64] N. E. West, N. Lechtzin, C. A. Merlo et al., "Appropriate goal level for 25-hydroxyvitamin D in cystic fibrosis," Chest, vol. 140, no. 2, pp. 469-474, 2011.

[65] T. L. Glover, B. R. Goodin, A. L. Horgas et al., "Vitamin D, race, and experimental pain sensitivity in older adults with knee osteoarthritis," Arthritis \& Rheumatism, vol. 64, no. 12, pp. 3926-3935, 2012.

[66] G. Högberg, S. A. Gustafsson, T. Hällström, T. Gustafsson, B. Klawitter, and M. Petersson, "Depressed adolescents in a caseseries were low in vitamin $\mathrm{D}$ and depression was ameliorated by vitamin D supplementation," Acta Paediatrica, vol. 101, no. 7, pp. 779-783, 2012.

[67] S. Basaran, R. Guzel, I. Coskun-Benlidayi, and F. Guler-Uysal, "Vitamin D status: effects on quality of life in osteoporosis among Turkish women," Quality of Life Research, vol. 16, no. 9, pp. 1491-1499, 2007.

[68] R. Vieth, S. Kimball, A. Hu, and P. G. Walfish, "Randomized comparison of the effects of the vitamin D3 adequate intake versus $100 \mathrm{mcg}$ (4000 IU) per day on biochemical responses and the wellbeing of patients," Nutrition Journal, vol. 3, article 8, 2004.

[69] V. Kunadian, G. A. Ford, B. Bawamia, W. Qiu, and J. E. Manson, "Vitamin D deficiency and coronary artery disease: a review of the evidence," American Heart Journal, vol. 167, no. 3, pp. 283291, 2014.

[70] H. A. Bischoff-Ferrari, D. P. Kiel, B. Dawson-Hughes et al., "Dietary calcium and serum 25-hydroxyvitamin D status in relation to BMD among U.S. adults," Journal of Bone and Mineral Research, vol. 24, no. 5, pp. 935-942, 2009.

[71] T. Penney, M. Ploughman, M. W. Austin, D. G. Behm, and J. M. Byrne, "Determining the activation of gluteus medius and the validity of the single leg stance test in chronic non-specific low back pain," Archives of Physical Medicine and Rehabilitation, vol. 95, no. 10, pp. 1969-1976, 2014.

[72] K. H. Cho, J. W. Beom, T. S. Lee, J. H. Lim, T. H. Lee, and J. H. Yuk, "Trunk muscles strength as a risk factor for nonspecific low back pain: a pilot study," Annals of Rehabilitation Medicine, vol. 38, no. 2, pp. 234-240, 2014. 
[73] H. A. Bischoff, H. B. Stähelin, W. Dick et al., "Effects of vitamin $\mathrm{D}$ and calcium supplementation on falls: a randomized controlled trial," Journal of Bone and Mineral Research, vol. 18, no. 2, pp. 343-351, 2003.

[74] M. Pfeifer, B. Begerow, and H. W. Minne, "Vitamin D and muscle function," Osteoporosis International, vol. 13, no. 3, pp. 187-194, 2002.

[75] R. U. Simpson, G. A. Thomas, and A. J. Arnold, "Identification of 1,25-dihydroxyvitamin: D3 receptors and activities in muscle," The Journal of Biological Chemistry, vol. 260, no. 15, pp. 8882-8891, 1985.

[76] H. A. Bischoff, M. Borchers, F. Gudat et al., "In situ detection of 1,25-dihydroxyvitamin $\mathrm{D}_{3}$ receptor in human skeletal muscle tissue," The Histochemical Journal, vol. 33, no. 1, pp. 19-24, 2001.

[77] O. H. Sørensen, B. Lund, B. Saltin et al., "Myopathy in bone loss of ageing: improvement by treatment with $1 \alpha$-hydroxycholecalciferol and calcium," Clinical Science, vol. 56, no. 2, pp. 157-161, 1979.

[78] M. Pfeifer, B. Begerow, H. W. Minne et al., "Vitamin D status, trunk muscle strength, body sway, falls, and fractures among 237 postmenopausal women with osteoporosis," Experimental and Clinical Endocrinology \& Diabetes, vol. 109, no. 2, pp. 8792, 2001.

[79] K. E. Broe, T. C. Chen, J. Weinberg, H. A. Bischoff-Ferrari, M. F. Holick, and D. P. Kiel, "A higher dose of vitamin D reduces the risk of falls in nursing home residents: a randomized, multipledose study," Journal of the American Geriatrics Society, vol. 55, no. 2, pp. 234-239, 2007.

[80] L. Flicker, K. Mead, C. Nowson et al., "Risk factors for falls in older women in residential care in Australia," Journal of Bone and Mineral Research, vol. 16, supplement 1, p. S170, 2001.

[81] P. Geusens, C. Vandevyver, J. Vanhoof, J.-J. Cassiman, S. Boonen, and J. Raus, "Quadriceps and grip strength are related to vitamin D receptor genotype in elderly nonobese women," Journal of Bone and Mineral Research, vol. 12, no. 12, pp. 2082-2088, 1997.

[82] L. M. Shinchuk and M. F. Holick, "Vitamin D and rehabilitation: improving functional outcomes," Nutrition in Clinical Practice, vol. 22, no. 3, pp. 297-304, 2007.

[83] D. A. Fernandes de Abreu, D. Eyles, and F. Féron, "Vitamin D, a neuro-immunomodulator: implications for neurodegenerative and autoimmune diseases," Psychoneuroendocrinology, vol. 34, supplement 1, pp. S265-S277, 2009.

[84] A. V. Kalueff and P. Tuohimaa, "Neurosteroid hormone vitamin $\mathrm{D}$ and its utility in clinical nutrition," Current Opinion in Clinical Nutrition and Metabolic Care, vol. 10, no. 1, pp. 12-19, 2007.

[85] H. H. Zakon, "The effects of steroid hormones on electrical activity of excitable cells," Trends in Neurosciences, vol. 21, no. 5, pp. 202-207, 1998.

[86] F.-S. Wu, T. T. Gibbs, and D. H. Farb, "Pregnenolone sulfate: a positive allosteric modulator at the $\mathrm{N}$-methyl-D-aspartate receptor," Molecular Pharmacology, vol. 40, no. 3, pp. 333-336, 1991.

[87] A. G. Mensah-Nyagan, L. Meyer, V. Schaeffer, C. Kibaly, and C. Patte-Mensah, "Evidence for a key role of steroids in the modulation of pain," Psychoneuroendocrinology, vol. 34, supplement 1, pp. S169-S177, 2009.

[88] C. Carlberg and M. J. Campbell, "Vitamin D receptor signaling mechanisms: integrated actions of a well-defined transcription factor," Steroids, vol. 78, no. 2, pp. 127-136, 2013.
[89] I. Neveu, P. Naveilhan, F. Jehan et al., "1,25-dihydroxyvitamin $\mathrm{D}_{3}$ regulates the synthesis of nerve growth factor in primary cultures of glial cells," Molecular Brain Research, vol. 24, no. 1-4, pp. 70-76, 1994.

[90] J. Brown, J. I. Bianco, J. J. McGrath, and D. W. Eyles, "1,25Dihydroxyvitamin $\mathrm{D}_{3}$ induces nerve growth factor, promotes neurite outgrowth and inhibits mitosis in embryonic rat hippocampal neurons," Neuroscience Letters, vol. 343, no. 2, pp. 139-143, 2003.

[91] S. Riaz, M. Malcangio, M. Miller, and D. R. Tomlinson, "A vitamin $\mathrm{D}_{3}$ derivative (CB1093) induces nerve growth factor and prevents neurotrophic deficits in streptozotocin-diabetic rats," Diabetologia, vol. 42, no. 11, pp. 1308-1313, 1999.

[92] E. Garcion, N. Wion-Barbot, C. N. Montero-Menei, F. Berger, and D. Wion, "New clues about vitamin D functions in the nervous system," Trends in Endocrinology and Metabolism, vol. 13, no. 3, pp. 100-105, 2002.

[93] F. Marchand, M. Perretti, and S. B. McMahon, "Role of the immune system in chronic pain," Nature Reviews Neuroscience, vol. 6, no. 7, pp. 521-532, 2005.

[94] L. McKelvey, G. D. Shorten, and G. W. O’Keeffe, "Nerve growth factor-mediated regulation of pain signalling and proposed new intervention strategies in clinical pain management," Journal of Neurochemistry, vol. 124, no. 3, pp. 276-289, 2013.

[95] C. J. Woolf, "Phenotypic modification of primary sensory neurons: the role of nerve growth factor in the production of persistent pain," Philosophical Transactions of the Royal Society B: Biological Sciences, vol. 351, no. 1338, pp. 441-448, 1996.

[96] L. R. Harms, T. H. J. Burne, D. W. Eyles, and J. J. McGrath, "Vitamin D and the brain," Best Practice \& Research: Clinical Endocrinology \& Metabolism, vol. 25, no. 4, pp. 657-669, 2011.

[97] L. D. Brewer, V. Thibault, K.-C. Chen, M. C. Langub, P. W. Landfield, and N. M. Porter, "Vitamin D hormone confers neuroprotection in parallel with downregulation of L-type calcium channel expression in hippocampal neurons," Journal of Neuroscience, vol. 21, no. 1, pp. 98-108, 2001.

[98] S. J. Kiraly, M. A. Kiraly, R. D. Hawe, and N. Makhani, "Vitamin $\mathrm{D}$ as a neuroactive substance: review," TheScientificWorldJournal, vol. 6, pp. 125-139, 2006.

[99] R. S. Griffin, M. Costigan, G. J. Brenner et al., "Complement induction in spinal cord microglia results in anaphylatoxin C5amediated pain hypersensitivity," Journal of Neuroscience, vol. 27, no. 32, pp. 8699-8708, 2007.

[100] M. Tsuda, K. Inoue, and M. W. Salter, "Neuropathic pain and spinal microglia: a big problem from molecules in 'small' glia," Trends in Neurosciences, vol. 28, no. 2, pp. 101-107, 2005.

[101] M. Hewison, "Vitamin D and the immune system: new perspectives on an old theme," Endocrinology and Metabolism Clinics of North America, vol. 39, no. 2, pp. 365-379, 2010.

[102] D. Feldman, A. Krishnan, J. Moreno, S. Swami, D. M. Peehl, and S. Srinivas, "Vitamin D inhibition of the prostaglandin pathway as therapy for prostate cancer," Nutrition Reviews, vol. 65, no. 8, part 2, pp. S113-S115, 2007.

[103] J. D. Richardson and M. R. Vasko, "Cellular mechanisms of neurogenic inflammation," The Journal of Pharmacology and Experimental Therapeutics, vol. 302, no. 3, pp. 839-845, 2002.

[104] J. J. Letterio and A. B. Roberts, "Regulation of immune responses by TGF-beta," Annual Review of Immunology, vol. 16, pp. 137-161, 1998.

[105] L. Leung and C. M. Cahill, "TNF- $\alpha$ and neuropathic pain-a review," Journal of Neuroinflammation, vol. 7, article 27, 2010. 
[106] H. F. Deluca and M. T. Cantorna, "Vitamin D: its role and uses in immunology," The FASEB Journal, vol. 15, no. 14, pp. 2579-2585, 2001.

[107] Y. Cury, G. Picolo, V. P. Gutierrez, and S. H. Ferreira, "Pain and analgesia: the dual effect of nitric oxide in the nociceptive system," Nitric Oxide, vol. 25, no. 3, pp. 243-254, 2011.

[108] E. Garcion, L. Sindji, G. Leblondel, P. Brachet, and F. Darcy, "1, 25-dihydroxyvitamin $\mathrm{D}_{3}$ regulates the synthesis of gammaglutamyl transpeptidase and glutathione levels in rat primary astrocytes," Journal of Neurochemistry, vol. 73, no. 2, pp. 859$866,1999$.

[109] K. Takahashi, Y. Nakayama, H. Horiuchi et al., "Human neutrophils express messenger RNA of vitamin D receptor and respond to lalpha,25-dihydroxyvitamin D3," Immunopharmacology and Immunotoxicology, vol. 24, no. 3, pp. 335-347, 2002.

[110] N. M. Perkins and D. J. Tracey, "Hyperalgesia due to nerve injury: role of neutrophils," Neuroscience, vol. 101, no. 3, pp. 745$757,2000$.

[111] J. Lemire, "1,25-dihydroxyvitamin $\mathrm{D}_{3}$-a hormone with immunomodulatory properties," Zeitschrift für Rheumatologie, vol. 59, supplement 1, pp. 24-27, 2000.

[112] D. W. Eyles, S. Smith, R. Kinobe, M. Hewison, and J. J. McGrath, "Distribution of the vitamin D receptor and $1 \alpha$-hydroxylase in human brain," Journal of Chemical Neuroanatomy, vol. 29, no. 1, pp. 21-30, 2005.

[113] G. F. Jirikowski, U. W. Kauntzer, A. E. E. Dief, and J. D. Caldwell, "Distribution of vitamin D binding protein expressing neurons in the rat hypothalamus," Histochemistry and Cell Biology, vol. 131, no. 3, pp. 365-370, 2009.

[114] R. E. S. Anglin, Z. Samaan, and S. D. Walter, "Vitamin D deficiency and depression in adults: systematic review and metaanalysis," British Journal of Psychiatry, vol. 202, no. 2, pp. 100107, 2013.

[115] S. C. Gominak and W. E. Stumpf, "The world epidemic of sleep disorders is linked to vitamin D deficiency," Medical Hypotheses, vol. 79, no. 2, pp. 132-135, 2012.

[116] F. Baeke, T. Takiishi, H. Korf, C. Gysemans, and C. Mathieu, "Vitamin D: modulator of the immune system," Current Opinion in Pharmacology, vol. 10, no. 4, pp. 482-496, 2010.

[117] L. Imeri and M. R. Opp, "How (and why) the immune system makes us sleep," Nature Reviews Neuroscience, vol. 10, no. 3, pp. 199-210, 2009.

[118] L. Clevenger, A. Schrepf, D. Christensen et al., "Sleep disturbance, cytokines, and fatigue in women with ovarian cancer," Brain, Behavior, and Immunity, vol. 26, no. 7, pp. 1037-1044, 2012.

[119] M. R. Opp, “Cytokines and sleep," Sleep Medicine Reviews, vol. 9, no. 5, pp. 355-364, 2005.

[120] M. Opp, J. Born, and M. Irwin, "Sleep and the immune system," in Psychoneuroimmunology, R. Ader, Ed., pp. 579-618, Elsevier Academic Press, Burlington, Mass, USA, 2007.

[121] J. M. Krueger, F. J. Obál, J. Fang, T. Kubota, and P. Taishi, “The role of cytokines in physiological sleep regulation," Annals of the New York Academy of Sciences, vol. 933, pp. 211-221, 2001.

[122] M. Haack, E. Sanchez, and J. M. Mullington, "Elevated inflammatory markers in response to prolonged sleep restriction are associated with increased pain experience in healthy volunteers," Sleep, vol. 30, no. 9, pp. 1145-1152, 2007.

[123] D. E. McCarty, A. Reddy, Q. Keigley, P. Y. Kim, and A. A. Marino, "Vitamin D, race, and excessive daytime sleepiness," Journal of Clinical Sleep Medicine, vol. 8, no. 6, pp. 693-697, 2012.
[124] K. Chopra and V. Arora, "An intricate relationship between pain and depression: clinical correlates, coactivation factors and therapeutic targets," Expert Opinion on Therapeutic Targets, vol. 18, no. 2, pp. 159-176, 2014.

[125] M. I. Maes, "Evidence for an immune response in major depression: a review and hypothesis," Progress in Neuro-psychopharmacology and Biological Psychiatry, vol. 19, no. 1, pp. 11-38, 1995.

[126] G. J. Summer, E. A. Romero-Sandoval, O. Bogen, O. A. Dina, S. G. Khasar, and J. D. Levine, "Proinflammatory cytokines mediating burn-injury pain," Pain, vol. 135, no. 1-2, pp. 98-107, 2008.

[127] N. Üçeyler, T. Eberle, R. Rolke, F. Birklein, and C. Sommer, “Differential expression patterns of cytokines in complex regional pain syndrome," Pain, vol. 132, no. 1-2, pp. 195-205, 2007.

[128] C. L. Raison, L. Capuron, and A. H. Miller, "Cytokines sing the blues: Inflammation and the pathogenesis of depression," Trends in Immunology, vol. 27, no. 1, pp. 24-31, 2006.

[129] Y. Dowlati, N. Herrmann, W. Swardfager et al., "A meta-analysis of cytokines in major depression," Biological Psychiatry, vol. 67, no. 5, pp. 446-457, 2010.

[130] I. J. Russell, H. Vaeroy, M. Javors, and F. Nyberg, "Cerebrospinal fluid biogenic amine metabolites in fibromyalgia/fibrositis syndrome and rheumatoid arthritis," Arthritis and Rheumatism, vol. 35, no. 5, pp. 550-556, 1992.

[131] J. J. Mann and K. M. Malone, "Cerebrospinal fluid amines and higher-lethality suicide attempts in depressed inpatients," Biological Psychiatry, vol. 41, no. 2, pp. 162-171, 1997.

[132] L. C. Campbell, D. J. Clauw, and F. J. Keefe, "Persistent pain and depression: a biopsychosocial perspective," Biological Psychiatry, vol. 54, no. 3, pp. 399-409, 2003.

[133] A. J. Dunn, "Effects of cytokines and infections on brain neurochemistry," Clinical Neuroscience Research, vol. 6, no. 1-2, pp. 52-68, 2006.

[134] D. Brambilla, S. Franciosi, M. R. Opp, and L. Imeri, "Interleukin-1 inhibits firing of serotonergic neurons in the dorsal raphe nucleus and enhances GABAergic inhibitory postsynaptic potentials," European Journal of Neuroscience, vol. 26, no. 7, pp. 1862-1869, 2007.

[135] A. Ellis and D. L. H. Bennett, "Neuroinflammation and the generation of neuropathic pain," British Journal of Anaesthesia, vol. 111, no. 1, pp. 26-37, 2013.

[136] P. H. Finan, B. R. Goodin, and M. T. Smith, "The association of sleep and pain: an update and a path forward," Journal of Pain, vol. 14, no. 12, pp. 1539-1552, 2013.

[137] S. González, D. Moreno-Delgado, E. Moreno et al., "Circadianrelated heteromerization of adrenergic and dopamine $\mathrm{D} 4$ receptors modulates melatonin synthesis and release in the pineal gland," PLoS Biology, vol. 10, no. 6, Article ID e1001347, 2012.

[138] C. A. Naranjo, L. K. Tremblay, and U. E. Busto, "The role of the brain reward system in depression," Progress in NeuroPsychopharmacology and Biological Psychiatry, vol. 25, no. 4, pp. 781-823, 2001.

[139] P. B. Wood, "Role of central dopamine in pain and analgesia," Expert Review of Neurotherapeutics, vol. 8, no. 5, pp. 781-797, 2008.

[140] P. B. Wood, "Stress and dopamine: implications for the pathophysiology of chronic widespread pain," Medical Hypotheses, vol. 62, no. 3, pp. 420-424, 2004.

[141] H. Foo and P. Mason, "Brainstem modulation of pain during sleep and waking," Sleep Medicine Reviews, vol. 7, no. 2, pp. 145154, 2003. 
[142] D. C. Nascimento, M. L. Andersen, D. C. Hipólide, J. N. Nobrega, and S. Tufik, "Pain hypersensitivity induced by paradoxical sleep deprivation is not due to altered binding to brain $\mu$-opioid receptors," Behavioural Brain Research, vol. 178, no. 2, pp. 216-220, 2007.

[143] O. E. Ukponmwan, J. Rupreht, and M. R. Dzoljic, "REM sleep deprivation decreases the antinociceptive property of enkephalinase-inhibition, morphine and cold-water-swim," General Pharmacology, vol. 15, no. 3, pp. 255-258, 1984.

[144] H. A. Baghdoyan, "Hyperalgesia induced by REM sleep loss: a phenomenon in search of a mechanism," Sleep, vol. 29, no. 2, pp. 137-139, 2006.

[145] A. M. Kshatri, H. A. Baghdoyan, and R. Lydic, "Cholinomimetics, but not morphine, increase antinociceptive behavior from pontine reticular regions regulating rapid-eye-movement sleep," Sleep, vol. 21, no. 7, pp. 677-685, 1998.

[146] P. L. Delgado, "Depression: the case for a monoamine deficiency," The Journal of Clinical Psychiatry, vol. 61, no. 6, pp. 7-11, 2000.

[147] H. L. Fields and A. I. Basbaum, "Central nervous system mechanisms of pain modulation," in Textbook of Pain, P. Wall and R. Melzack, Eds., pp. 243-257, Churchill Livingstone, New York, NY, USA, 1994.

[148] J. Levine and Y. Taiwo, "Inflammatory pain," in Textbook of Pain, P. Wall and R. Melzack, Eds., pp. 45-56, Churchill Livingstone, New York, NY, USA, 1994.

[149] P. M. Dougherty and W. D. Willis, "Enhanced responses of spinothalamic tract neurons to excitatory amino acids accompany capsaicin-induced sensitization in the monkey," Journal of Neuroscience, vol. 12, no. 3, pp. 883-894, 1992.

[150] D. J. Claliw, "The pathogenesis of chronic pain and fatigue syndromes, with special reference to fibromyalgia," Medical Hypotheses, vol. 44, no. 5, pp. 369-378, 1995.

[151] R. Dantzer, J. C. O’Connor, G. G. Freund, R. W. Johnson, and K. W. Kelley, "From inflammation to sickness and depression: when the immune system subjugates the brain," Nature Reviews. Neuroscience, vol. 9, no. 1, pp. 46-56, 2008.

[152] J. W. Kasckow, D. Baker, and T. D. Geracioti Jr., "Corticotropinreleasing hormone in depression and post-traumatic stress disorder," Peptides, vol. 22, no. 5, pp. 845-851, 2001.

[153] M. Schäfer, S. A. Mousa, Q. Zhang, L. Carter, and C. Stein, "Expression of corticotropin-releasing factor in inflamed tissue is required for intrinsic peripheral opioid analgesia," Proceedings of the National Academy of Sciences of the United States of America, vol. 93, no. 12, pp. 6096-6100, 1996. 


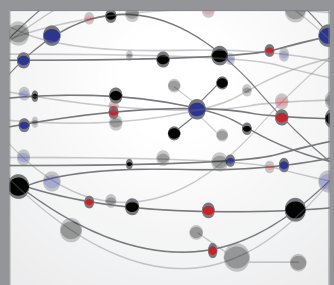

The Scientific World Journal
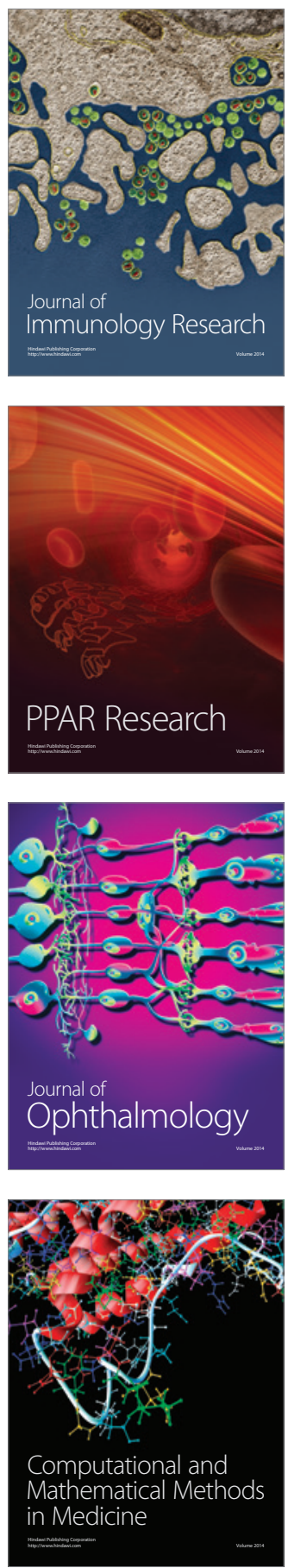

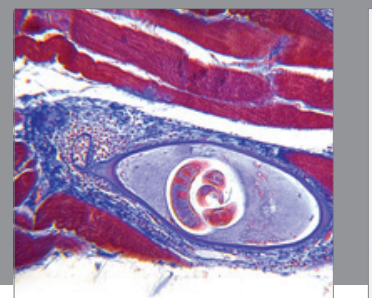

Gastroenterology

Research and Practice
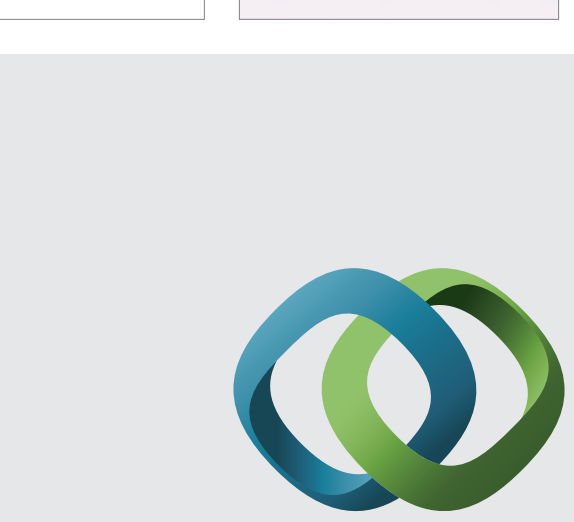

\section{Hindawi}

Submit your manuscripts at

http://www.hindawi.com
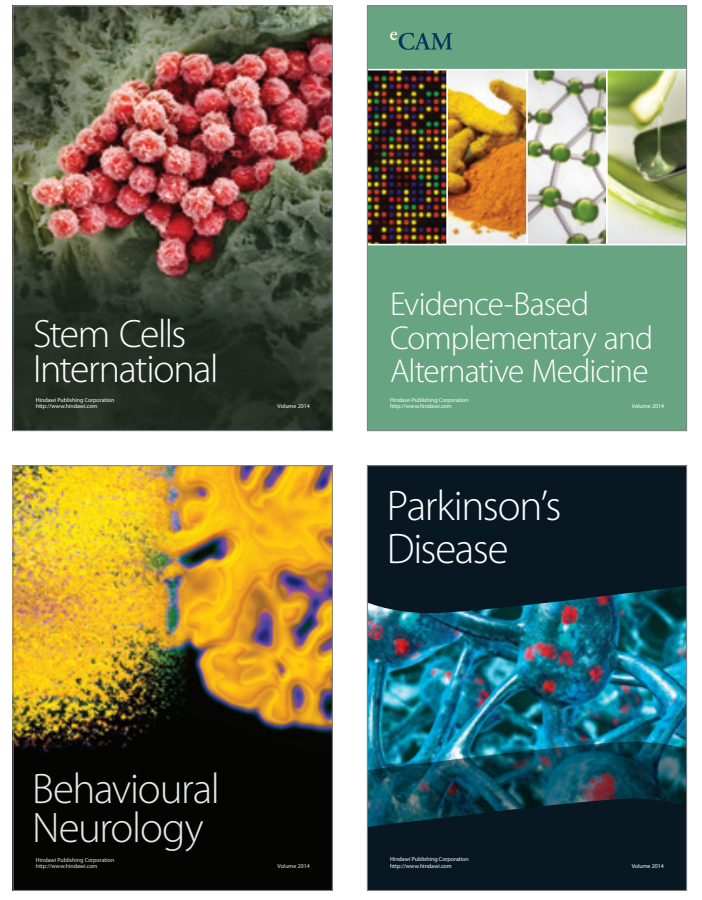
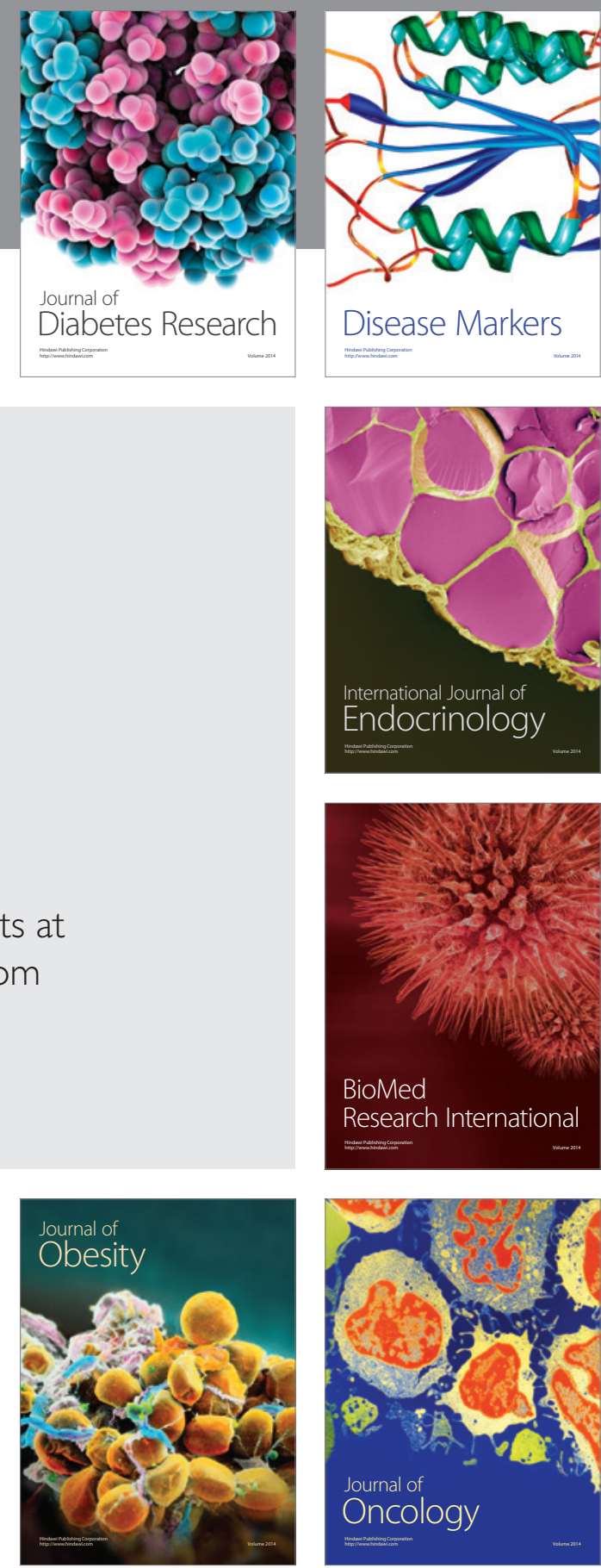

Disease Markers
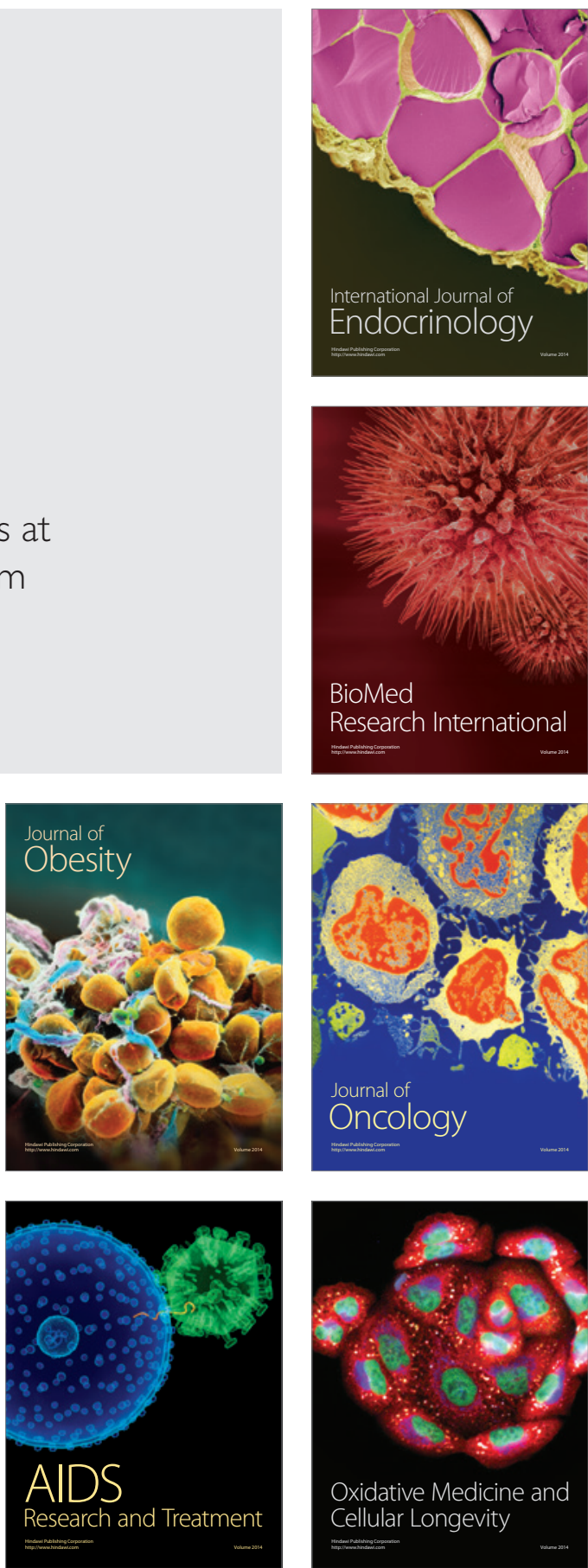